OPEN ACCESS

Edited by:

Michael Gänzle,

University of Alberta, Canada

Reviewed by:

Zuzana Hruska

Mississippi State University, USA

Sara Spilimbergo,

University of Padova, Italy

${ }^{*}$ Correspondence:

Xiaojun Liao

liaoxjun@hotmail.com

Specialty section:

This article was submitted to

Food Microbiology

a section of the journal

Frontiers in Microbiology

Received: 26 June 2016

Accepted: 25 August 2016 Published: 07 September 2016

Citation:

Rao L, Zhao F, Wang Y, Chen F, Hu X and Liao X (2016) Investigating the Inactivation Mechanism of Bacillus subtilis Spores by High Pressure $\mathrm{CO}_{2}$.

Front. Microbiol. 7:1411. doi: 10.3389/fmicb.2016.01411

\section{Investigating the Inactivation Mechanism of Bacillus subtilis Spores by High Pressure $\mathrm{CO}_{2}$}

\author{
Lei Rao ${ }^{1,2,3}$, Feng Zhao ${ }^{2,3}$, Yongtao Wang ${ }^{2,3}$, Fang Chen ${ }^{2,3}$, Xiaosong $\mathrm{Hu}^{1,2,3}$ and \\ Xiaojun Liao ${ }^{1,2,3 *}$
}

\begin{abstract}
${ }^{1}$ Beijing Advanced Innovation Center for Food Nutrition and Human Health, College of Food Science and Nutritional Engineering, China Agricultural University, Beijing, China, ${ }^{2}$ National Engineering Research Center for Fruit and Vegetable Processing, Beijing, China, ${ }^{3}$ Key Lab of Fruit and Vegetable Processing, Ministry of Agriculture, Beijing, China
\end{abstract}

The objective of this study was to investigate the inactivation mechanism of Bacillus subtilis spores by high pressure $\mathrm{CO}_{2}$ (HPCD) processing. The spores of $B$. subtilis were subjected to heat at $0.1 \mathrm{MPa}$ or $\mathrm{HPCD}$ at $6.5-20 \mathrm{MPa}$, and $64-86^{\circ} \mathrm{C}$ for 0-120 min. The germination, the permeability of inner membrane (IM) and cortex, the release of pyridine-2, 6-dicarboxylic acid (DPA), and changes in the morphological and internal structures of spores were investigated. The HPCD-treated spores did not lose heat resistance and their DPA release was lower than the inactivation, suggesting that spores did not germinate during HPCD. The flow cytometry analysis suggested that the permeability of the IM and cortex of HPCD-treated spores was increased. Furthermore, the DPA of the HPCD-treated spores were released in parallel with their inactivation and the fluorescence photomicrographs showed that these treated spores were stained by propidium iodide, ensuring that the permeability of IM of spores was increased by HPCD. The scanning electron microscopy photomicrographs showed that spores were crushed into debris or exhibited a hollowness on the surface, and the transmission electron microscopy photomicrographs exhibited an enlarged core, ruptured and indistinguishable IM and a loss of core materials in the HPCD-treated spores, indicating that HPCD damaged the structures of the spores. These findings suggested that HPCD inactivated $B$. subtilis spores by directly damaging the structure of the spores, rather than inducing germination of the spores.

Keywords: high pressure $\mathrm{CO}_{2}$, inactivation, Bacillus subtilis spores, mechanism, inner membrane damage

\section{INTRODUCTION}

Spores of a number of Bacillus and Clostridium species are extremely resistant to a variety of severe stresses including extreme temperatures (steam at $121^{\circ} \mathrm{C}$ ), desiccation, chemicals and radiation because of their unique structures (Setlow, 1995, 2006). These spores are common agents of food spoilage, foodborne illnesses, and detrimental changes to the organoleptic quality of food (Brown, 2000; Logan, 2012), which make them a significant problem in the food industry. Consequently, there is much interest in methods that inactivate these spores as well as the inactivation mechanisms.

Traditionally, spores are inactivated by heat at extremely high temperature $\left(121^{\circ} \mathrm{C}\right.$ or higher $)$ (Block, 2001). It is known that heat inactivates spores by damaging one or more proteins, most 
likely some enzymes involved in metabolism (Coleman et al., 2007, 2010). However, the identity of this key protein or proteins is not known. Although high temperature can effectively inactivate spores, it also can impart undesirable organoleptic changes and cause some detrimental effects to the nutritional quality of heat-sensitive food. Consequently, nonthermal technologies such as irradiation, pulsed electric fields, pulsed magnetic fields, high hydrostatic pressure (HHP), and high pressure $\mathrm{CO}_{2}$ (HPCD), have been proposed as foodprocessing methods. Among these technologies, the HHP is the most studied, and shows the potential to inactivate bacterial spores when combined with mild temperatures (Black et al., 2007a; Reineke et al., 2013b). However, the large investment cost due to the extremely high processing pressure and the non-continuous nature of the process hamper the industrial applications and commercialization of the HHP (Devlieghere et al., 2004; Estrada-Girón et al., 2005; Garcia-Gonzalez et al., 2007; Perrut, 2012).

The inactivation effect of HPCD was first shown in 1951 on Escherichia coli (Fraser, 1951). In recent years, HPCD treatment has been proposed as an alternative non-thermal pasteurization technique for foods because of its environmentally benign nature $\left(\mathrm{CO}_{2}\right.$ is nontoxic), as well as the much lower pressure (generally lower than $30 \mathrm{MPa}$ ) compared with the high pressure (100-600 MPa) employed in the HHP processing (GarciaGonzalez et al., 2007). Previous studies indicate that HPCD at less than $30 \mathrm{MPa}$ and at 20 to $40^{\circ} \mathrm{C}$ can effectively inactivate the vegetative forms of pathogenic and spoilage bacteria, yeasts, and molds, but has no effect on bacterial spores (Spilimbergo and Bertucco, 2003; Damar and Balaban, 2006; Zhang et al., 2006b; Garcia-Gonzalez et al., 2007; Perrut, 2012; Rao et al., 2015a). Several studies suggested that cycled-pressure HPCD or $\mathrm{HPCD}$ at temperature $\geq 60^{\circ} \mathrm{C}$ can effectively inactivate bacterial spores, and different inactivation mechanisms have been proposed (Spilimbergo et al., 2002; Spilimbergo and Bertucco, 2003; Spilimbergo et al., 2003; Bae et al., 2009).

One possible inactivation mechanism is that the spores are first activated and germinated, and then inactivated during the HPCD treatment. As reported in a previous study (Spilimbergo et al., 2002), a tyndallization effect (approximately 3.5-log reduction) is observed in Bacillus subtilis spores as a result of cycled-pressure (30 cycles/h, $\Delta \mathrm{P}=8 \mathrm{MPa}$ ) HPCD treatment at $15 \mathrm{MPa}$ and $36^{\circ} \mathrm{C}$ for $30 \mathrm{~min}$, and the inactivation mechanism is explained as follows: the initial pressure cycles induce spore activation such that germination takes place during the holding time between two different cycles. The germinated spores are inactivated during the cycles that follow (Spilimbergo et al., 2002). It is hypothesized that a combined treatment of temperature (at least $60^{\circ} \mathrm{C}$ ) and $\mathrm{CO}_{2}$ induces shock in the spore structure, which leads to their activation. The spores start their germination during a long contact time of HPCD treatment. The geminated spores became more sensitive to the antimicrobial effect of $\mathrm{CO}_{2}$, which ultimately results in their inactivation (Spilimbergo and Bertucco, 2003; Spilimbergo et al., 2003). However, there is no data to support the claim that the spores are truly germinated during HPCD treatment in these studies. Although it has been reported that $40 \%$ of Bacillus coagulans spores and $70 \%$ of
Bacillus licheniformis spores are germinated by HPCD at $35^{\circ} \mathrm{C}$ for 120 min (Furukawa et al., 2004), it is not clear whether the spores can be induced to germinate by HPCD at temperature $\geq 60^{\circ} \mathrm{C}$.

Another possible inactivation mechanism is that HPCD inactivates spores by directly damaging the spore structures. A previous study used scanning electron microscopy (SEM) and energy-filtering transmission electron microscopy (EFTEM) methods to investigate the morphological changes of Alicyclobacillus acidoterrestris spores treated by HPCD at $10 \mathrm{MPa}$ and $70^{\circ} \mathrm{C}$ for $30 \mathrm{~min}$ (Bae et al., 2009). The SEM photomicrographs revealed that the treated spores were crushed and exhibit a high degree of hollowness on the surface. The EF-TEM photomicrographs showed an enlarged periplasmic space and a loss of cytoplasm in the treated spores. Based on these images, the authors concluded that HPCD directly affected and inactivated the A. acidoterrestris spores (Bae et al., 2009). However, the germination of spores was not examined in the study, and there are no data to exclude the possibility that spores may first germinate, and later be inactivated by damage to their structures. Moreover, it is also not clear how HPCD damages the spore structures, which needs further research. Recently, the flow cytometry method (FCM) has been used to assess the structural changes of high pressure treated spores stained with SYTO 16 and propidium iodide (PI) (Mathys et al., 2007; Reineke et al., 2013a). It is reported that the dormant and decoated spores are not stained by SYTO16. However, after hydrolysis of the spore cortex, the membrane-permeable SYTO 16 can permeate into the spore core and exhibit green fluorescence by binding to the nucleic acid (Black et al., 2005; Black et al., 2007b). Therefore, SYTO 16 can be designed as an indicator of the damage of the spores' cortex. Meanwhile, PI red fluorescence nucleic acid dye is membrane impermeable, and used to identify the damage of the spores' inner membrane (IM) (Mathys et al., 2007).

In our previous work, $B$. subtilis spores were inactivated by HPCD at temperatures higher than $82^{\circ} \mathrm{C}$, and exhibited nonlinear inactivation curves with a shoulder and a log-linear region (Rao et al., 2015b). The inactivation included two steps as follows: the spores first lost their resistance at the shoulder regions, and then were inactivated at the log-linear regions. The loss of resistance of the spores at the shoulder regions was explained as follows: (i) spores were induced to germinate by HPCD and lost resistance; (ii) spore structures including cortex and IM as well as some important proteins crucial to spore germination and outgrowth were damaged by HPCD. Therefore, more work is needed to determine the real reasons. In the current work, we examined the spore germination by determining the loss of heat resistance (Furukawa et al., 2004; Shah et al., 2008) and the pyridine-2, 6-dicarboxylic acid (DPA) release of HPCDtreated spores (Yi and Setlow, 2010; Setlow et al., 2016). We have also investigated the permeability of the cortex and IM of spores by the flow cytometry method (FCM) and confocal laser scanning microscopy (CLSM), as well as the release of the core material of DPA. Moreover, we have visually demonstrated changes to the surface and internal structure of spores by SEM and TEM. 


\section{MATERIALS AND METHODS}

\section{Strain and Spore Preparation}

Bacillus subtilis 168 was obtained from the China General Microbiological Culture Collection Center (Beijing, China), and the sporulation was carried out as previously described (Rao et al., 2015b). Overnight cultures of Bacillus strain grown in nutrient broth were transferred to sporulation agar plates, nutrient agar containing $50 \mu \mathrm{g} / \mathrm{mL} \mathrm{Mn}^{2+}$. After 1 week incubation at $37^{\circ} \mathrm{C}$, the spores were harvested in a sterile flask by flushing the surface of the culture with sterile distilled water and scrapping the surface with sterile glass microscope slide. The spores collected were washed three times by centrifugation at 7,000 $\times g$ and $4^{\circ} \mathrm{C}$ for $15 \mathrm{~min}$, resuspended in sterile distilled water with a concentration of approximately $10^{9} \mathrm{CFU} / \mathrm{ml}$, and stored at $4^{\circ} \mathrm{C}$ until they were used. All spores (>99\%) used in this work were free of growing and sporulating cells, germinated spores, and cell debris, as determined with a BX45-72P15 phase contrast microscope (Olympus, Japan). The concentration of the spore suspension was adjusted to approximately $10^{7} \mathrm{CFU} / \mathrm{mL}$ before treatments.

\section{HPCD Treatment}

The treatment conditions were shown in Table 1. HPCD treatment was performed with a batch HPCD system (Liao et al., 2007). For each experiment, $20 \mathrm{~mL}$ of the spores suspended in sterile distilled water was transferred to a $50 \mathrm{~mL}$ sterile glass tube and the tube was covered with a plastic film with a $0.22 \mu \mathrm{m}$ membrane filter in the center of aeration to prevent microbial contamination. As the pressure vessel of the HPCD system reached the experimental temperature $\left(64-66^{\circ} \mathrm{C}\right.$ or $\left.84-86^{\circ} \mathrm{C}\right)$, the sample tubes were placed in the pressure vessel. Next, the vessel was pressurized by the plunger pump to 6.5 or $20 \mathrm{MPa}$ within 0.1 or $2.5 \mathrm{~min}$, respectively. After holding for required treatment time, the depressurization was performed by opening the pressure relief valve at the $\mathrm{CO}_{2}$ outlet on the pressure vessel. The depressurization time was $0.5 \mathrm{~min}$ or $2.5 \mathrm{~min}$ for 6.5 or $20 \mathrm{MPa}$, respectively. After HPCD, the sample tubes were taken out from the vessel and analyzed immediately. The $\mathrm{CO}_{2}$ purity was $99.5 \%$ in all the experiment treatments.

The inactivation of the spore suspensions by heat at $86^{\circ} \mathrm{C}$ was carried out at $0.1 \mathrm{MPa}$ without the addition of $\mathrm{CO}_{2}$ using a water bath. Similar to HPCD treatment, $20 \mathrm{~mL}$ of the spore suspension was transferred to a $50 \mathrm{~mL}$ sterile glass tube and immersed in a water bath equilibrated at $86^{\circ} \mathrm{C}$ for $0-30 \mathrm{~min}$. The experiment was done in triplicate. After treatment, the sample tubes were taken out and immediately analyzed.

\section{Enumeration of Surviving Spores}

The number of surviving spores was determined by the viable plate count method. Each sample was serially (1:10) diluted with sterile distilled water and pour-plated on nutrient agar in duplicate. The plates were incubated at $37^{\circ} \mathrm{C}$ for $24 \mathrm{~h}$. After incubation, the colonies were counted.

\section{Measurement of Germination}

As it was known that the spores would lose heat resistance and release almost all the DPA after germination (Setlow, 2003), the germination of spores during HPCD treatment was investigated by determining the loss of heat resistance and DPA release (Shah et al., 2008; Setlow et al., 2016). The spores treated by HPCD were subjected to wet heat at $80^{\circ} \mathrm{C}$ for $20 \mathrm{~min}$, then diluted and pour-plated on nutrient agar. Following incubation at $37^{\circ} \mathrm{C}$ for $24 \mathrm{~h}$, the colonies were counted. Germination was expressed as the change in colonies before and after exposure to heat.

The DPA release was measured using the fluorescence method (Hindle and Hall, 1999). The treated spores were centrifuged at $7,000 \times g$ and $4^{\circ} \mathrm{C}$ for $10 \mathrm{~min}$, and assaying DPA in the supernatant fluid was carried out by its fluorescence with $\mathrm{Tb}^{3+}$ in a 96-well plate. One hundred microliter of supernatant fluid were added to $100 \mu \mathrm{L} 20 \mu \mathrm{mol} / \mathrm{L}$ terbium (III) chloride hexahydrate buffered with $1 \mathrm{~mol} / \mathrm{L}$ acetic acid at $\mathrm{pH}$ 5.6. All the samples were analyzed with a microplate reader (Multiskan MK3, Thermo, USA). Samples were excited at $270 \mathrm{~nm}$, and emission spectra were collected at $545 \mathrm{~nm}$. The total amount of DPA in each individual batch was determined after autoclaving at $121^{\circ} \mathrm{C}$ for 20 min (Zhang et al., 2006a), which was used as a positive control while the one in untreated spores was used as a negative control. HPCD-induced DPA release was calculated by the following equation:

$$
\mathrm{DPA} \%=\frac{\mathrm{F}_{1}-\mathrm{F}_{0}}{\mathrm{~F}_{2}-\mathrm{F}_{0}}
$$

Where $F_{0}, F_{1}$, and $F_{2}$ were the fluorescence intensity of untreated spores, HPCD treated spores, and autoclaved spores, respectively.

\section{Flow Cytometry Analysis}

Samples for flow cytometry were prepared with two DNA staining dyes according to a reported method (Reineke et al., 2013a). The dyes propidium iodide (PI) (Sigma-Aldrich) and SYTO 16 (Invitrogen) are both able to stain DNA. The membrane-permeable SYTO 16 acts as an indicator for cortex damage (Black et al., 2005), and the membrane-impermeable PI indicates the IM damage (Mathys et al., 2007). The treated spore suspensions were adjusted to concentrations of about $10^{7}$

TABLE 1 | High pressure $\mathrm{CO}_{2}$ (HPCD) treatment conditions for different figures.

\begin{tabular}{lccccc}
\hline & Temperature $\left({ }^{\circ} \mathbf{C}\right)$ & Pressure $(\mathbf{M P a})$ & Holding time $(\mathbf{m i n})$ & Pressurization (min) & Depressurization $(\mathbf{m i n})$ \\
\hline Figure 1A & $64-66$ & 6.5 & $0-60$ & 0.1 & 2.5 \\
Figure 1B & $64-66$ & 20 & $0-60$ & 0.1 & 2.5 \\
Figure 1C & $84-86$ & 6.5 & $0-30$ & 2.5 & 0.5 \\
Figure 1D & $84-86$ & 20 & $0-30$ & 2.5
\end{tabular}


spores/mL in sterile distilled water. The concentration of the fluorescent dyes in the spore suspensions were $15 \mu \mathrm{mol} / \mathrm{L} \mathrm{PI}$ and $0.5 \mu \mathrm{mol} / \mathrm{L}$ SYTO 16. Afterward, the samples were stored in the dark at room temperature for 45 min (Pappas et al., 2015).

Stained samples were then analyzed with an Accuri C6 (BD Accuri Cytometer Inc., USA) flow cytometry equipped with a $488 \mathrm{~nm}, 50 \mathrm{~mW}$ laster. SYTO 16 fluorescence was quantified with the FL1 detector at $530 \pm 15 \mathrm{~nm}$. PI fluorescence was quantified with the FL2 detector at $585 \pm 20 \mathrm{~nm}$. The forward scatter threshold was set at 5000 to ensure that the small spores were not omitted as events. Spores were analyzed at a nominal flow rate of $14 \mu \mathrm{L} / \mathrm{min}$, with a stream core diameter of $10 \mu \mathrm{m}$. All samples were evaluated after 30000 events had been recorded. The live gate, in which spores are all alive and cannot be stained with PI or SYTO16, was based on untreated spores as negative controls, while the dead gate, where the spores are all dead and can be stained with PI or SYTO16, was based on the spores exposed to $121^{\circ} \mathrm{C}$ for $20 \mathrm{~min}$ as positive controls.

\section{Fluorescence Analysis}

The untreated, autoclaved $\left(121^{\circ} \mathrm{C}, 20 \mathrm{~min}\right)$, heat treated $\left(86^{\circ} \mathrm{C}\right.$, $20 \mathrm{~min}$ ), and HPCD treated, spore suspensions were adjusted to about $10^{7}$ spores $/ \mathrm{mL}$ in sterile distilled water and stained with $15 \mu \mathrm{mol} / \mathrm{L}$ PI for $45 \mathrm{~min}$ at room temperature. The stained spore samples were imaged with a Zeiss LSM710 confocal laser scanning microscope (Zeiss, Germany) with $100 \times$ oil lens. The fluorescent photomicrographs were acquired with the Zeiss AIM image browser software (Zeiss, Germany).

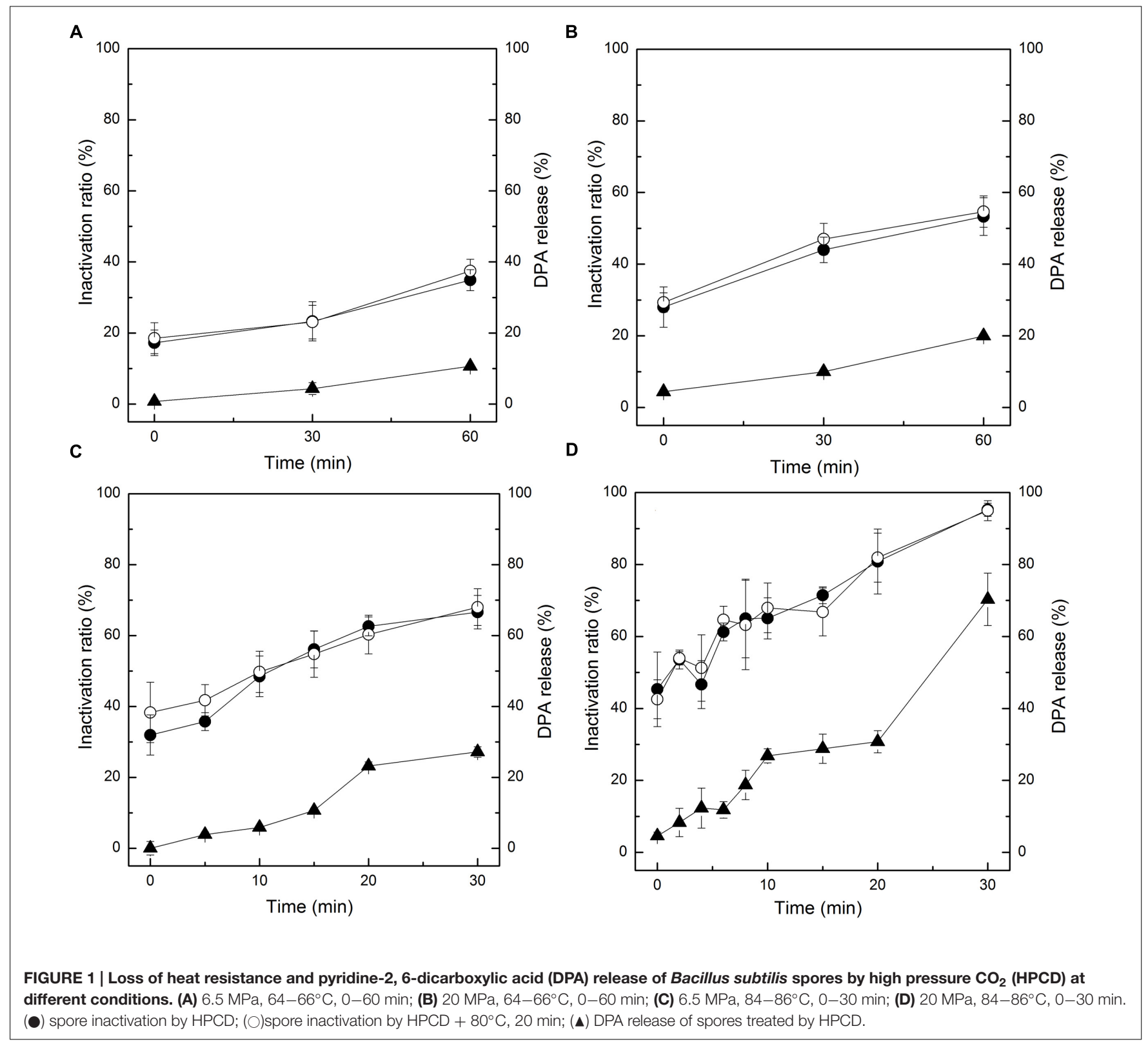




\section{Spore Preparation for SEM and TEM}

For both SEM and TEM analysis, spore suspensions were centrifuged $(10,000 \times g)$ and prefixed in $2.5 \%$ glutaraldehyde (Sigma-Aldrich) overnight at room temperature, rinsed three times in $0.1 \mathrm{~mol} / \mathrm{L}$ phosphate-buffered saline (PBS) for $15 \mathrm{~min}$ and centrifuged again $(10,000 \times g)$. The spore pellets were postfixed in $1 \%$ osmium tetroxide (Sigma-Aldrich) for $90 \mathrm{~min}$ and rinsed three times in $0.1 \mathrm{~mol} / \mathrm{L}$ PBS for $15 \mathrm{~min}$, and subsequently dehydrated with ethanol series (50, 70, 80, 90 and $100 \%)$. For SEM, the dehydrated spore samples were stored at $-20^{\circ} \mathrm{C}$ for $20 \mathrm{~min}$ and subjected to critical point drying. The spore samples were sputter coated in about $12 \mathrm{~nm}$ of gold and palladium under vacuum, and subsequently analyzed by SEM (FEI Quanta 200, FEI, Czech Republic). For TEM, the dehydrated spore samples were embedded in epoxy resin and kept at $37^{\circ} \mathrm{C}$ overnight followed by $60^{\circ} \mathrm{C}$ for $24 \mathrm{~h}$. The resin blocks were cut into ultrathin sections of $70 \mathrm{~nm}$ with an ultramicrotome (Lecia EM UC6, Leica, Germany) and stained with 3\% aqueous lead citrate and $3 \%$ aqueous uranyl acetate. Finally, the spore samples were examined by TEM (H-7650B, Hitachi, Japan).

\section{Data Analysis}

Flow cytometry data were analyzed using the FlowJo version 7.6.1 software (FlowJo). Analysis of variance (ANOVA) was carried out by using software PASW statistic 18 (SPSS, USA). ANOVA tests were carried out for statistical significance of group differences at $\alpha=0.05$ level. All experiments were carried out in triplicate.

\section{RESULTS}

\section{Germination Detection}

Figures 1A-D show the germination of the HPCD-treated spores estimated by the loss of heat resistance. The inactivation of the HPCD-treated spores increased with increasing time. After HPCD treatment at the temperature of $64-66^{\circ} \mathrm{C}$ for $30 \mathrm{~min}$ (Figures 1A,B), the inactivation was $23.3 \%$ at $6.5 \mathrm{MPa}$ and $44.0 \%$ at $20 \mathrm{MPa}$. When the temperature was increased to $84-$ $86^{\circ} \mathrm{C}$ (Figures 1C,D), the inactivation was increased to $66.6 \%$ at 6.5 $\mathrm{MPa}$ and $95.2 \%$ at $20 \mathrm{MPa}$. After all the HPCD-treated spores were subjected to heat treatment at $80^{\circ} \mathrm{C}$ for $20 \mathrm{~min}$, there were no changes in the inactivation of the treated spores $(P>0.05)$, indicating that there were no germinated spores in the HPCDtreated spores. The DPA release of the HPCD-treated spores was also determined. Similarly, the DPA release was increased with increasing the time. After HPCD treatment at $64-66^{\circ} \mathrm{C}$ for $30 \mathrm{~min}$ (Figures 1A,B), the DPA release was $4.3 \%$ at $6.5 \mathrm{MPa}$ and $10.0 \%$ at $20 \mathrm{MPa}$. When the temperature was increased to
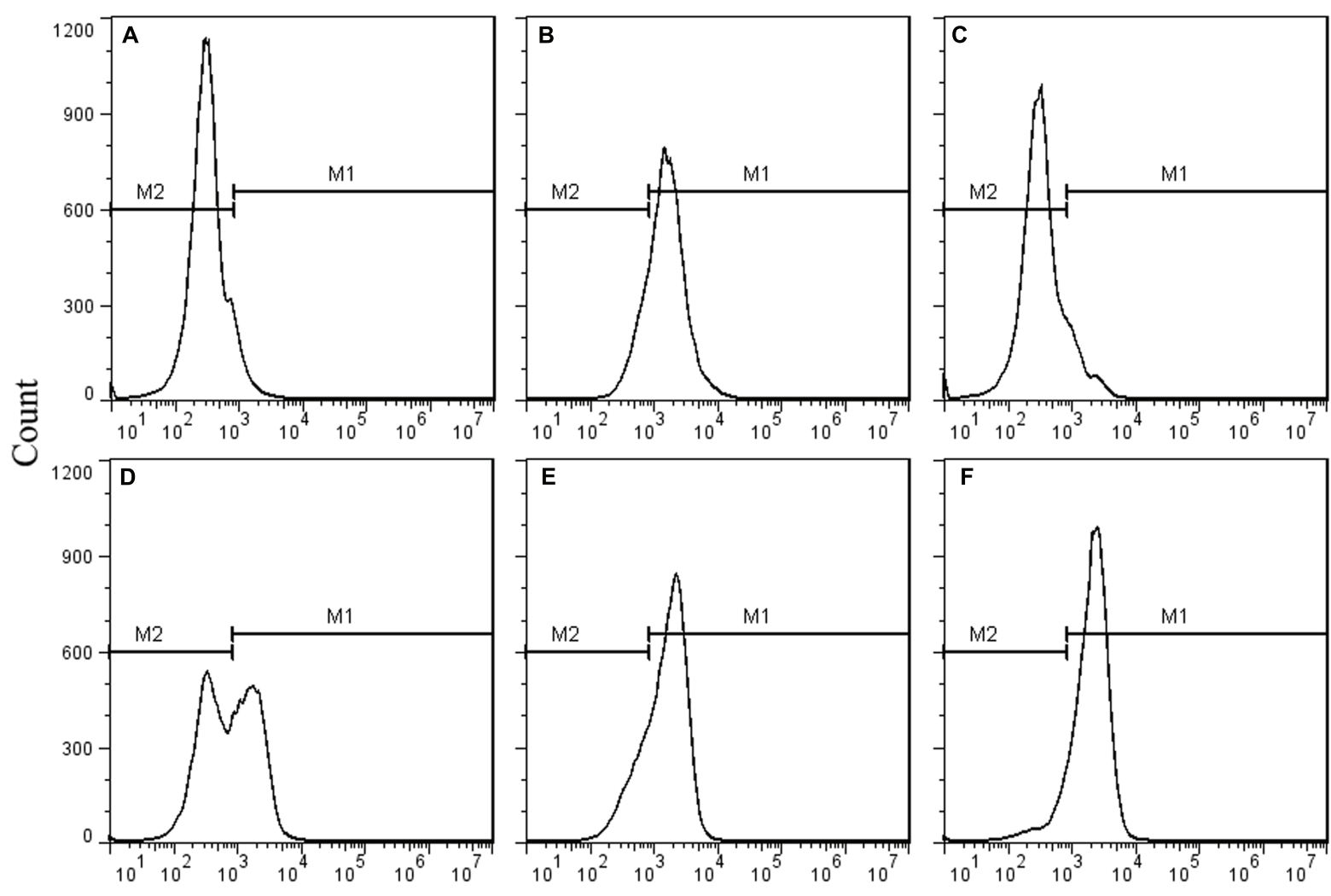

FL2-H

FIGURE 2 | Flow cytometry histograms of $B$. subtilis spores treated by HPCD at $20 \mathrm{MPa}, 84-86^{\circ} \mathrm{C}$ for $0-20$ min and stained by propidium iodide (PI). (A) untreated; (B) autoclaved at $121^{\circ} \mathrm{C}$ for $20 \mathrm{~min}$; (C) heat treated at $86^{\circ} \mathrm{C}$ for $20 \mathrm{~min}$; HPCD treated at $20 \mathrm{MPa}, 84-86^{\circ} \mathrm{C}$ for $0 \mathrm{~min}$ (D), $10 \mathrm{~min}$ (E), $20 \mathrm{~min}$ (F). 
$84-86^{\circ} \mathrm{C}$ (Figures 1C,D), the DPA release was $27.2 \%$ at $6.5 \mathrm{MPa}$ and $70.3 \%$ at $20 \mathrm{MPa}$. Obviously, the DPA release was much lower than the corresponding inactivation $(P<0.05)$, suggesting that a portion of the inactivated spores, rather than all of them, released the DPA.

\section{FCM Analysis}

As the spores were not germinated during the inactivation process by HPCD, the spores were presumed to be inactivated by damage to their structures. The permeability of the IM (Figure 2) and cortex (Figure 3) of spores were tested by FCM. The untreated spores were used as negative control, and the heat-treated spores at $121^{\circ} \mathrm{C}$ for $20 \mathrm{~min}$ (>7 log-reduction) were used as positive control. Meanwhile, the heat-treated spores at $86^{\circ} \mathrm{C}$ for $20 \mathrm{~min}$ ( $0.067 \mathrm{log}$-reduction) were used to do the comparison analysis with the HPCD-treated spores at $20 \mathrm{MPa}$ and $84-86^{\circ} \mathrm{C}$ for $0 \mathrm{~min}$ (0.15 log-reduction), $10 \mathrm{~min}(0.45$ log-reduction), and $20 \mathrm{~min}$ (0.85 log-reduction). As shown in Figure 2, the FCM histograms of red fluorescence distribution of the spores stained by PI were divided into two areas, M1 and M2. According to the histogram of the untreated spores (Figure 2A), M2 was the negative area in which the spores had intact IM and were not stained by PI, while M1 was the positive area, indicating that the IM was damaged, and the spores were stained by PI. Compared with the untreated spores, the fluorescence distribution of the heat-treated spores at $121^{\circ} \mathrm{C}$ for $20 \mathrm{~min}$ moved increasingly towards M1 (Figure 2B), indicating that the IM of the spores were damaged. Meanwhile, there was only a very slight increase of the fluorescence in M1 for the heat-treated spores at $86^{\circ} \mathrm{C}$ for $20 \mathrm{~min}$ (Figure $2 \mathrm{C}$ ), suggesting that these heattreated spores have intact IM. For the HPCD-treated spores at $20 \mathrm{MPa}$ and $84-86^{\circ} \mathrm{C}$ (Figures 2D-F), the fluorescence in M1 was increased, and the fluorescence distribution moved towards M1 with increased the time, indicating that the IM of spores was damaged during the HPCD treatment. Similar results are shown in Figure 3. According to the FCM histogram of green fluorescence distribution of the untreated spores (Figure 3A), M2 was the negative area in which the spores had intact cortex, and were not stained by SYTO 16, while M1 was the positive area, indicating that the cortex was damaged, and the spores were stained by SYTO 16. Compared with the untreated spores, the heat-treated spores at $121^{\circ} \mathrm{C}$ for 20 min showed a marked increase of the fluorescence in the M1 (Figure 3B), indicating damage to the cortex of spores. For the heat-treated spores at $86^{\circ} \mathrm{C}$ for $20 \mathrm{~min}$ (Figure $3 \mathrm{C}$ ), there was no change of the fluorescence in $\mathrm{M} 1$, suggesting that heat treatment at $86^{\circ} \mathrm{C}$ for
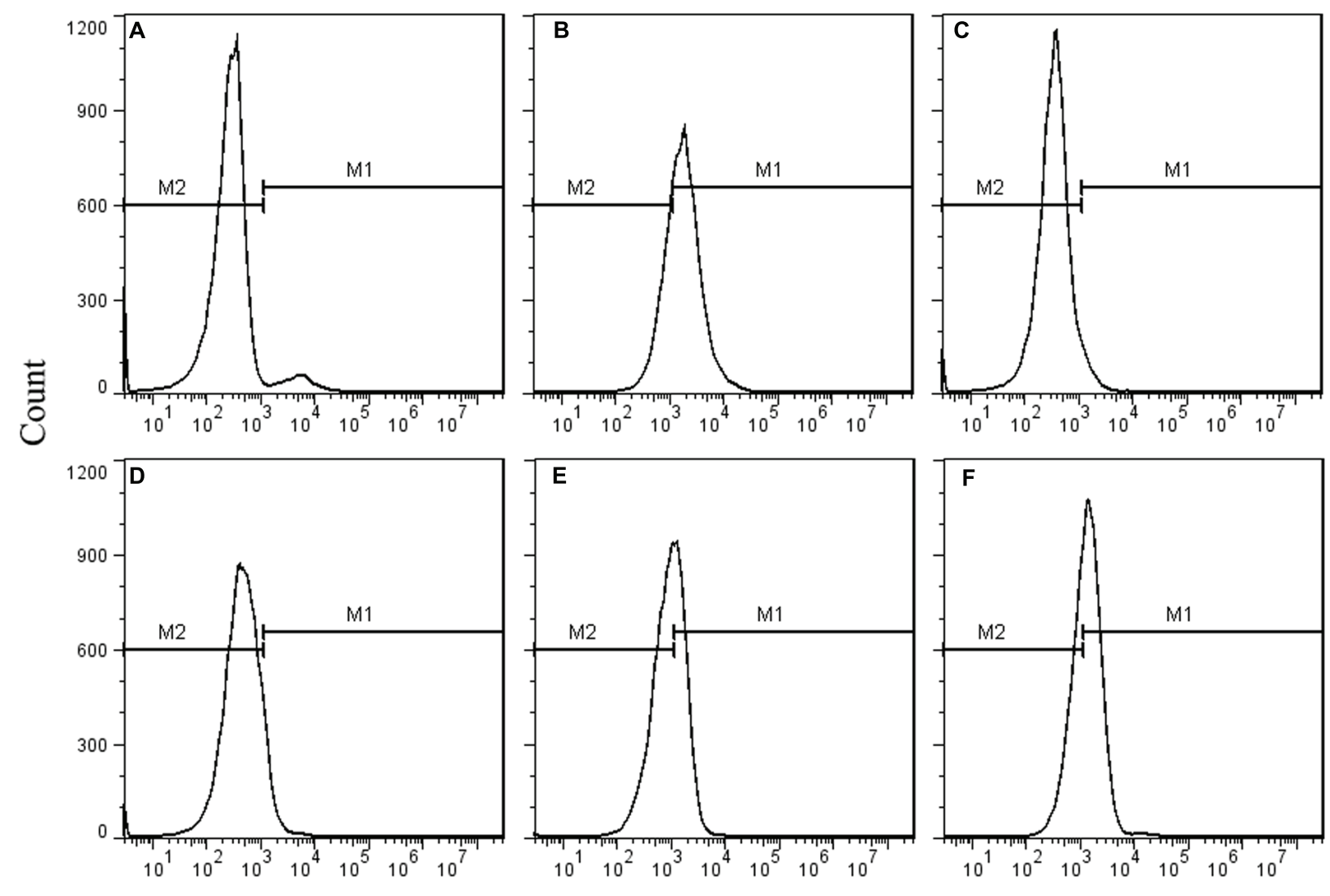

FL1-H

FIGURE 3 | Flow cytometry histograms of $B$. subtilis spores treated by HPCD at $20 \mathrm{MPa}, 84-86^{\circ} \mathrm{C}$ for $0-20$ min and stained by SYTO 16 . (A) untreated; (B) autoclaved at $121^{\circ} \mathrm{C}$ for $20 \mathrm{~min}$; (C) heat treated at $86^{\circ} \mathrm{C}$ for $20 \mathrm{~min}$; HPCD treated at $20 \mathrm{MPa}, 84-86^{\circ} \mathrm{C}$ for 0 min (D), $10 \mathrm{~min}$ (E), $20 \mathrm{~min}$ (F). 

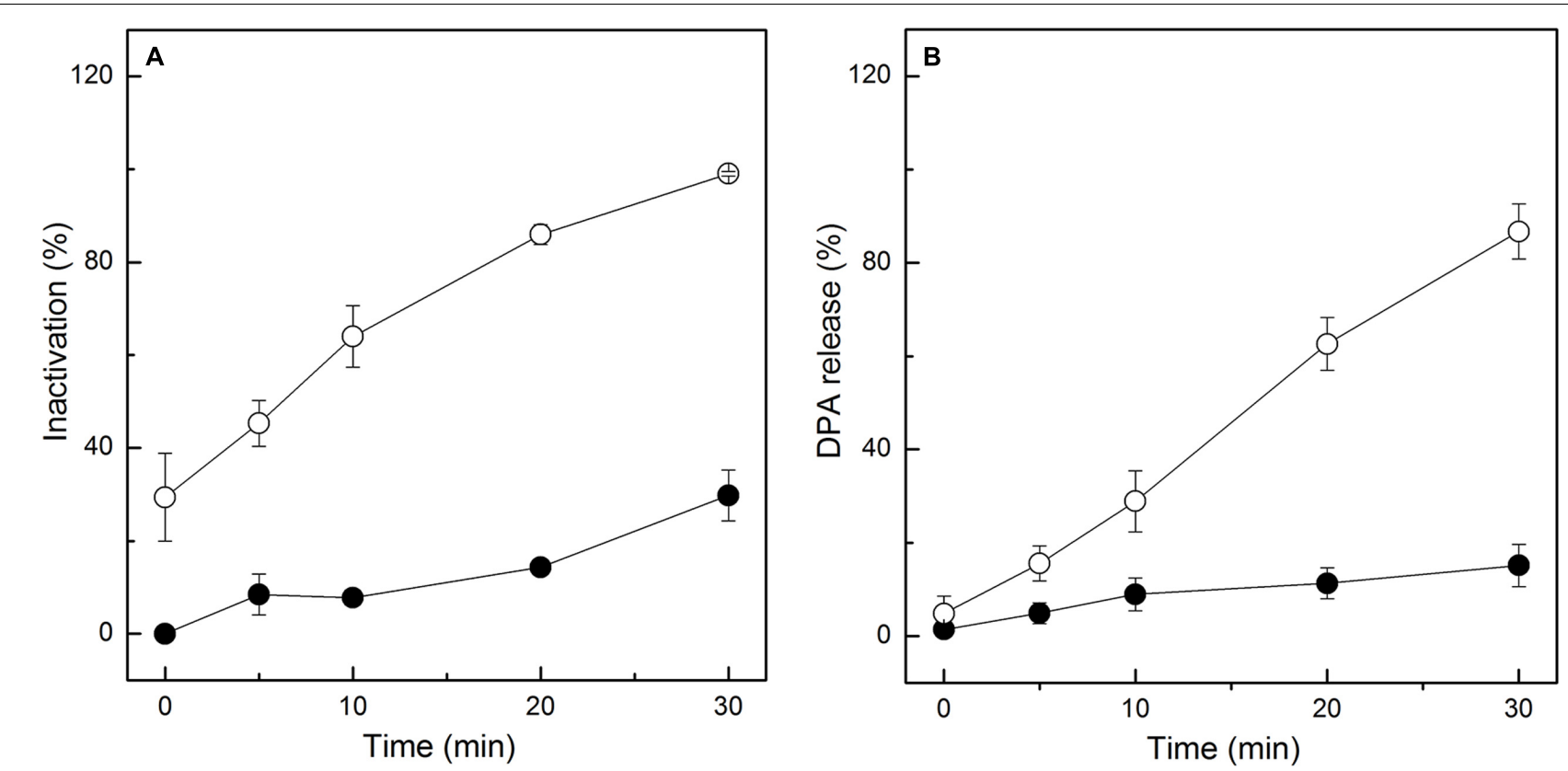

FIGURE 4 | Inactivation and DPA release of Bacillus subtilis spores treated by $\mathrm{HPCD}$ at $20 \mathrm{MPa}, 84-86^{\circ} \mathrm{C}$ for $0-30$ min $(\bigcirc)$ and heat at $86^{\circ} \mathrm{C}$ for 0-30 $\mathrm{min}(\mathbf{O})$. (A) Inactivation; (B) DPA release.

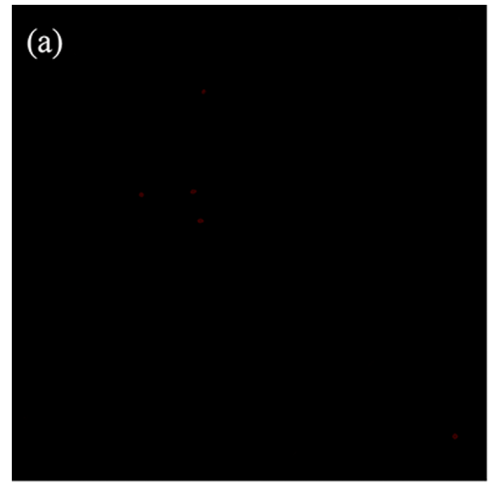

(d)

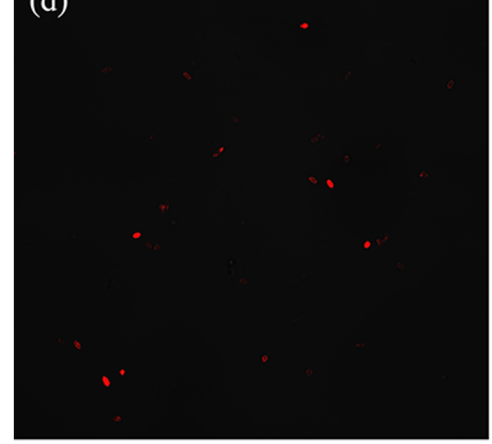

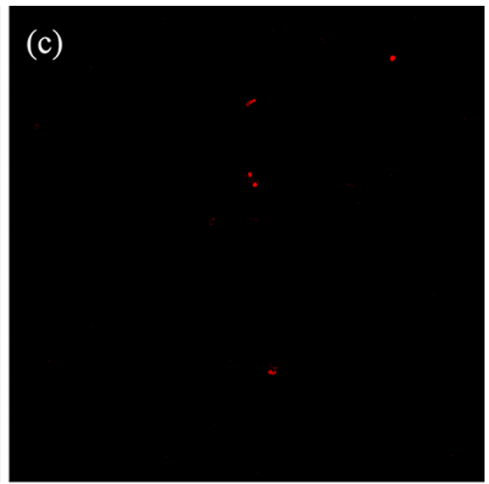

(e)

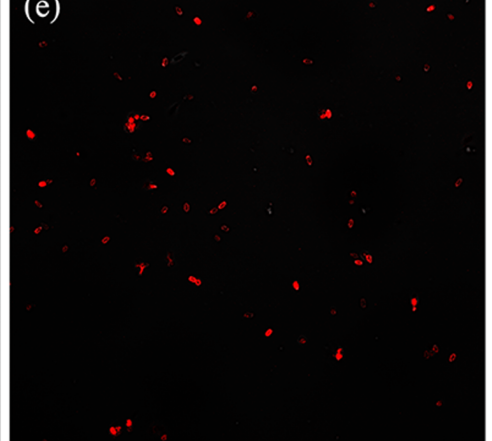

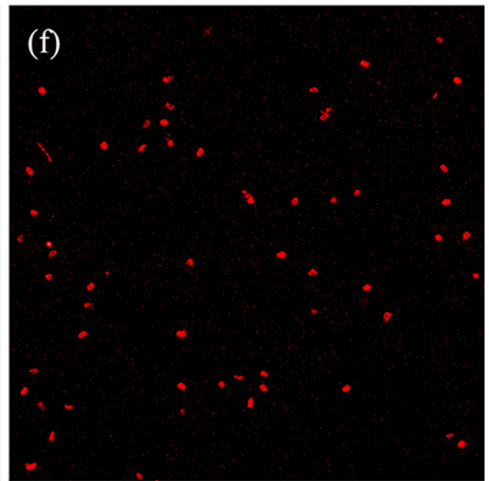

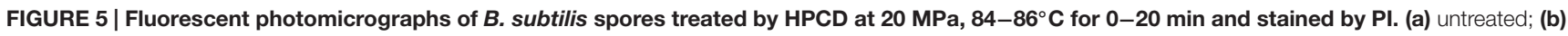
autoclaved at $121^{\circ} \mathrm{C}$ for $20 \mathrm{~min}$; (c) heat treated at $86^{\circ} \mathrm{C}$ for $20 \mathrm{~min}$; HPCD treated at $20 \mathrm{MPa}, 84-86^{\circ} \mathrm{C}$ for 0 min (d), 10 min (e), 20 min (f). The samples were imaged with $100 \times$ oil lens as detailed in the Section "Materials and Methods". 

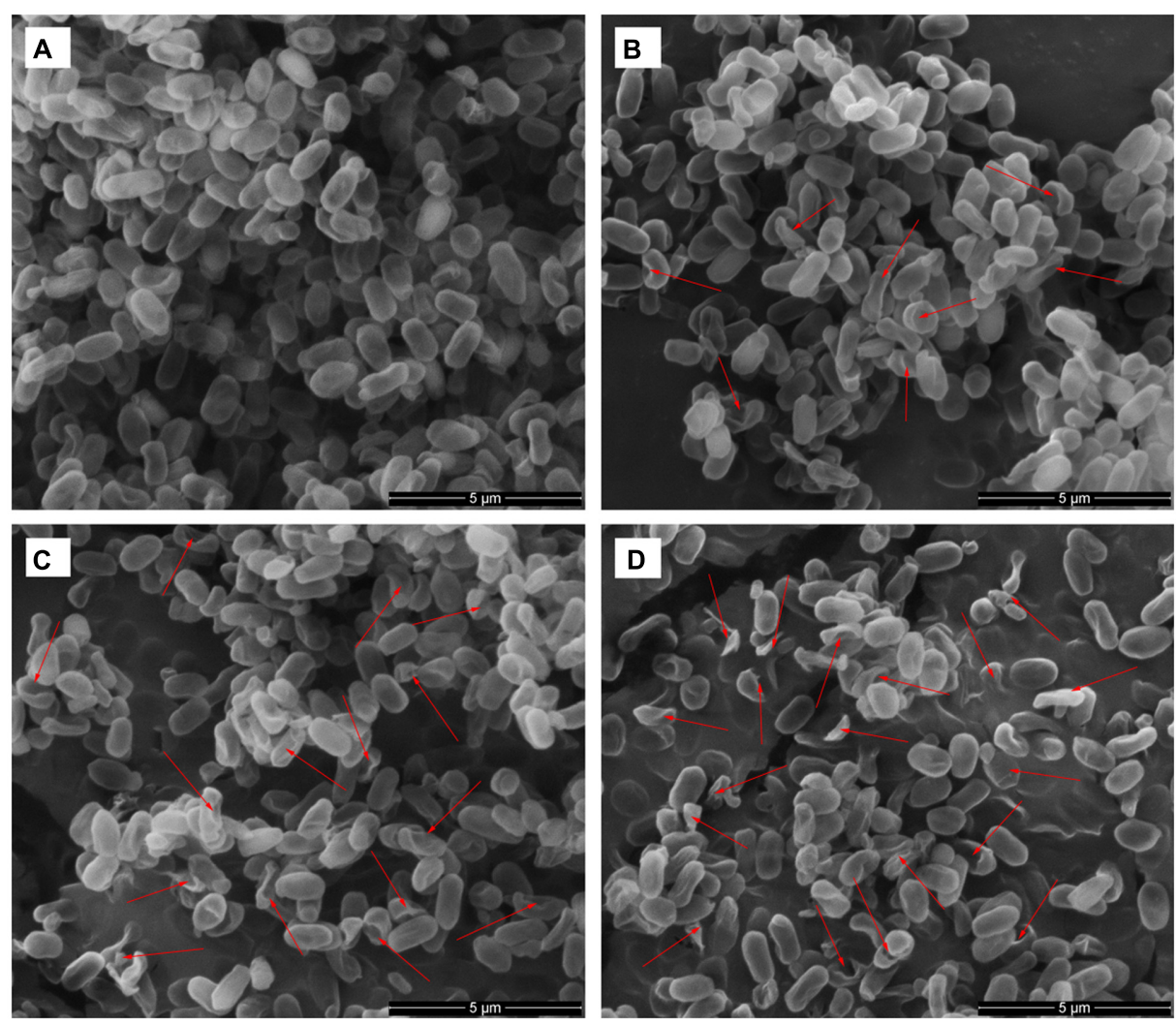

FIGURE 6 | Scanning electron microscopy photomicrographs of $B$. subtilis spores of untreated (A) or treated by $\mathrm{HPCD}$ at $20 \mathrm{MPa}$ and $84-86^{\circ} \mathrm{C}$ for $10 \mathrm{~min}(\mathrm{~B}), 20 \mathrm{~min}$ (C) and $30 \mathrm{~min}$ (D). Arrows indicate cell debris, and deformed or collapsed spores.

20 min did not damage the cortex of spores. For the HPCDtreated spores at $20 \mathrm{MPa}$ and $84-86^{\circ} \mathrm{C}$ (Figures 3D-F), the fluorescence distribution moved towards M1 with increased time, indicating that the cortex of spores was gradually damaged during HPCD treatment.

\section{DPA Release}

Given the results of the FCM analysis, further tests were needed to ensure the damage of the IM of spores. Thus, the release of DPA, main core material in spores, was determined after HPCD treatment at $20 \mathrm{MPa}$ and $84-86^{\circ} \mathrm{C}$ for $0-30 \mathrm{~min}$. Meanwhile, the heat-treated spores treated at $86^{\circ} \mathrm{C}$ for $0-30$ min were tested and compared with the HPCD-treated spores. With increased time, the inactivation of the HPCD-treated spores was increased, and the maximum value was $99.0 \%$ (Figure 4A). For the heat-treated spores, the inactivation was slowly increased with increased time, and the maximum value was $29.8 \%$ (Figure $4 \mathbf{A}$ ). Similar to the results of the inactivation, the release of DPA (Figure 4B) for the HPCD-treated spores was also increased with increased time, and the maximum value was $86.8 \%$, which indicated that the IM of most spores were damaged during the inactivation process by HPCD. For the heat-treated spores, the release of DPA (Figure 4B) was slightly increased with increased time, and the maximum value was $15.2 \%$, suggesting that most spores maintained an intact IM.

\section{CLSM Photomicrographs}

In addition to testing the DPA release, CLSM was used to image the PI stained spores and examine the permeability of the IM of spores. The untreated spores with intact IM were not stained by PI (Figure 5a) while the autoclaved spores were all dead and stained red by PI (Figure 5b). The heat-treated $\left(86^{\circ} \mathrm{C}, 20 \mathrm{~min}\right)$ spores $(0.067 \log$-reduction) were not stained (Figure 5c), indicating these spores retained an intact IM. For the spores treated by HPCD at $20 \mathrm{MPa}$ and $86^{\circ} \mathrm{C}$, most of the spores were not stained or stained peripherally at $0 \mathrm{~min}$ (0.15 log-reduction) (Figure 5d) and $10 \mathrm{~min}$ (0.45 log-reduction) (Figure 5e), while completely stained at $20 \mathrm{~min}(0.85 \mathrm{log}$ reduction) (Figure 5f), further ensuring that the IM of the spores was gradually damaged during the HPCD treatment.

\section{SEM and TEM Photomicrographs}

To visually confirm damage to the spore structures, SEM and TEM were used to examine the morphological changes of the spores during the inactivation process by HPCD treatment at $20 \mathrm{MPa}$ and $84-86^{\circ} \mathrm{C}$ for $10 \mathrm{~min}$ (Figures 6B and 7B), $20 \mathrm{~min}$ (85.9\% inactivation) (Figures 6C and 7C) and $30 \mathrm{~min}(99.0 \%$ inactivation) (Figures 6D and 7D). The SEM photomicrographs showed that the HPCD-treated spores were crushed into debris, or exhibited a high degree of hollowness on the surface with increased time (Figures 6B-D), whereas the untreated 

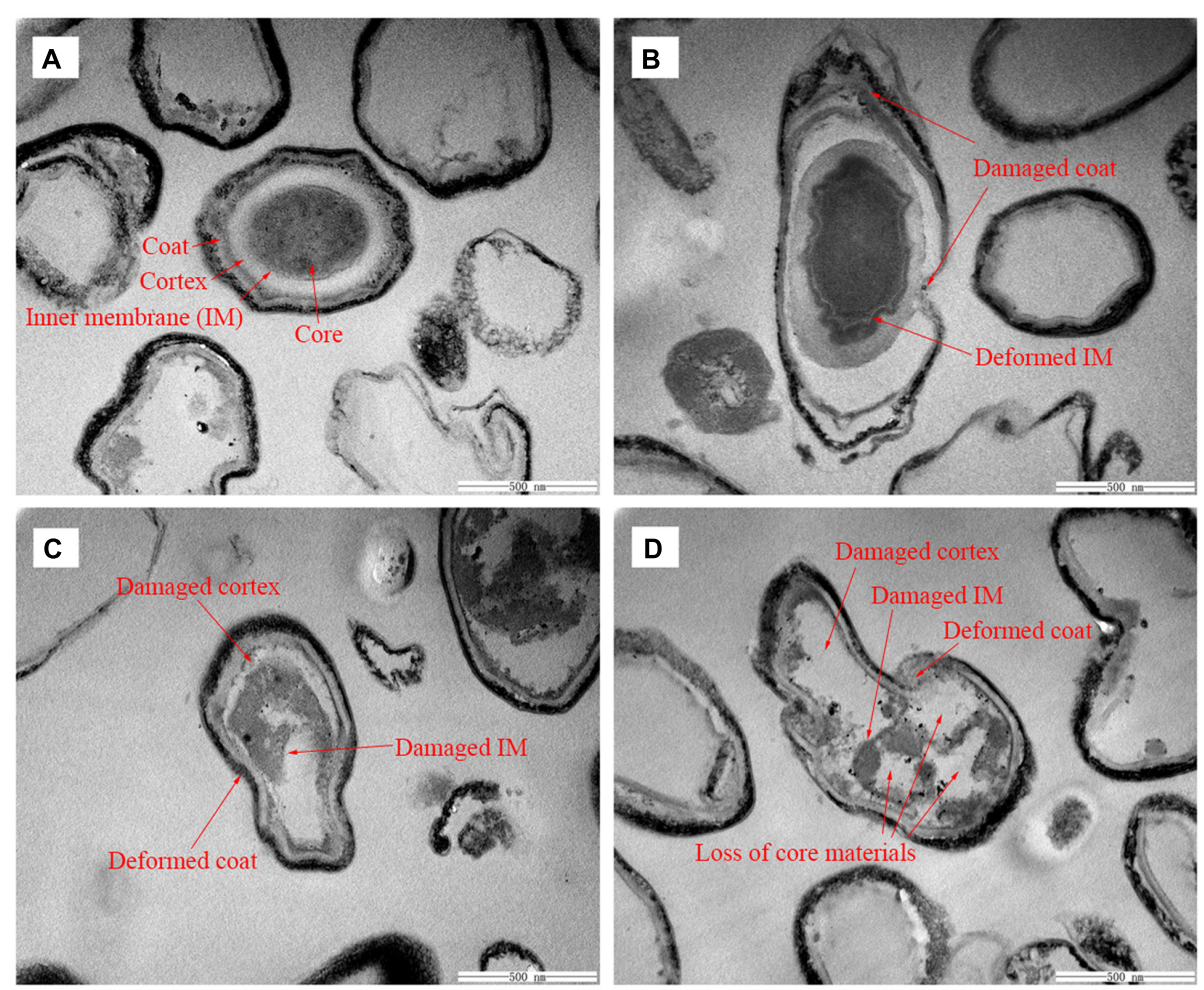

FIGURE 7 | Transmission electron microscopy photomicrographs of $B$. subtilis spores of untreated (A) or treated by $\mathrm{HPCD}$ at $20 \mathrm{MPa}$ and $84-86^{\circ} \mathrm{C}$ for $10 \mathrm{~min}(B), 20 \mathrm{~min}(C)$, and $30 \mathrm{~min}(D)$.

spores were intact planiform ellipsoids (Figure 6A). In the TEM photomicrographs, significant changes of the core area and the morphological structures of the HPCD-treated spores (Figures 7B-D) were observed compared with the untreated spores (Figure 7A). The treated spores showed an enlarged core and a loss of the core materials, and the IM of spores was ruptured (Figures 7C,D). Moreover, the coat of the treated spores was deformed (Figures 7B-D). These SEM and TEM photomicrographs further confirmed that HPCD damaged the spore structures.

\section{DISCUSSION}

In this study, the germination of spores was examined during the inactivation process by HPCD at different conditions (Figures 1A-D). As it is known that spores will lose heat resistance and release almost all the DPA after germination (Setlow, 2003; Yi and Setlow, 2010; Setlow et al., 2016), the loss of heat resistance and DPA release were used as indicators for spore germination (Shah et al., 2008; Setlow et al., 2016). Our results showed that there was no change in the population of the HPCDtreated spores after exposure to heat treatment at $80^{\circ} \mathrm{C}$ for $20 \mathrm{~min}$ (Figures 1A-D), suggesting that no germinated spores existed in the HPCD-treated spore population. Moreover, the DPA release was always lower than the inactivation of spores (Figures 1A-D), indicating that only some of the inactivated spores released DPA rather than all (Coleman et al., 2007). Thus, the inactivated spores did not undergo the germination process during the inactivation process by HPCD treatment. Indeed, there was evidence to support the premise that the spore germination may be suppressed under HPCD conditions. A previous report indicated that the germination of Bacillus cereus, Clostridium sporogenes, and Clostridium perfringens spores was inhibited completely by carbon dioxide at atmospheric pressure, 1.0 and 2.5 MPa, respectively (Enfors and Molin, 1978), and this inhibition of spore germination might be caused by low $\mathrm{pH}$ under the HPCD conditions. It was also reported that the optimum $\mathrm{pH}$ for pressure-induced germination at moderate pressure of $100 \mathrm{MPa}$, just like the nutrient-induced germination, was close to neutral ( $\mathrm{pH} 7.0$ ), and lowering the $\mathrm{pH}$ would strongly inhibit the germination (Sale et al., 1970; Bender and Marquis, 1982; Wuytack and Michiels, 2001). Another study found that reduction of $\mathrm{pH}$ from 7 to 5.5 completely inhibited spore germination of Clostridium botulinum 12885A (Blocher and Busta, 1985a). Similar results were reported for the C. botulinum and B. cereus spores at pH 4.5 (Blocher and Busta, 1985b), B. cereus and B. subtilis spores at pH 3.6 (Yi and Setlow, 2010). It was assumed that the inhibition of the spore germination in an acidic environment was induced by the inhibition of the germinant binding to the germinant receptors (GRs), which would block the commitment step of the germination (Blocher and Busta, 1985b; Yi and Setlow, 2010). This inhibition of the germinant binding was probably due to the protonation of a 
function group in or near the GRs (Blocher and Busta, 1985b). In our study, the HPCD treatment was conducted in a pure water $-\mathrm{CO}_{2}$ system, in which the $\mathrm{pH}$ was a strong function of pressure, but a weak function of temperature (Meyssami et al., 1992). With increased pressure, the $\mathrm{pH}$ decreased to approximately 3.0 at $5.5 \mathrm{MPa}$ and then remained constant (Meyssami et al., 1992). Obviously, spore germination would be inhibited at such a low $\mathrm{pH}$ value. Given our results and those of others, it was concluded that the inactivation of spores by HPCD was not attributed to spore germination.

As the inactivation of spores by HPCD was not due to the spore germination, the question of how HPCD inactivated spores, still remains. In fact, as the $\mathrm{CO}_{2}$ had smaller molecular weight and higher penetrability under the HPCD state than did the spore germinants (e g., L-valine, L-alanine, D-glucose), which were able to penetrate into to the spore cells and bind to the germinant receptors (GRs) in the IM (Setlow, 2003), the $\mathrm{CO}_{2}$ of HPCD could theoretically penetrate into the spores cells and act on the IM. In this study, the structural changes of spores during HPCD treatment were examined. The FCM analysis indicate that the permeability of the IM of HPCD-treated spores and cortex increased (Figures 2 and 3), which was due to the damage to these two structures by HPCD. This damage was confirmed by the large release of the main core material of DPA (Figure 4) and the CLSM photomicrographs (Figure 5) of spores after HPCD treatment. Moreover, the SEM and TEM photomicrographs further visually confirm the damage of the morphological structures of the HPCD-treated spores (Figures 6 and 7). Although our results indicated that the HPCD-inactivated spores exhibited structural damage, it was necessary to determine which specific structure was damaged to the point where it caused the spore inactivation. In the FCM results for the HPCD-treated spores at $20 \mathrm{MPa}$ and $84-86^{\circ} \mathrm{C}$ for $0 \mathrm{~min}$ (29.4\% inactivation) (Figures 2D and 3D), the red fluorescence in M1 was significantly increased (Figure 2D) compared with the untreated spores (Figure 2A), while the green fluorescence in M1 was not changed (Figure 3D) compared with the untreated ones (Figure 3A). This indicates that the damage to the spore IM occurred prior to inactivation and the damage to the spore cortex in large portion of the spores. Therefore, the damage of the IM of spores would be the reason for spore inactivation by HPCD. Similar results were reported in previous studies. It has been reported that $\mathrm{HPCD}+0.02 \% \mathrm{H}_{2} \mathrm{O}_{2}$ treatment at $27.5 \mathrm{MPa}$ and $40^{\circ} \mathrm{C}$ for 240 min effectively inactivated Bacillus atrophaeus (Zhang et al., 2006a) and Bacillus anthracis (Zhang et al., 2007) spores by $>6$ log-reduction. The TEM photomicrographs, DPA analysis and BacLight fluorescence results in these studies indicated that HPCD damaged the IM of spores, which allowed the penetration of $\mathrm{H}_{2} \mathrm{O}_{2}$ into the core and subsequent oxidation of the vital structures that caused spore death (Zhang et al., 2006a, 2007). A recent study achieved more than $6 \log$ inactivation of $B$. subtilis spores by HPCD $+0.0035-0.0055 \%$ peracetic acid (PAA) at 9.8 $\mathrm{MPa}$ and $35^{\circ} \mathrm{C}$ for $25 \mathrm{~min}$, and the authors suggested that the inactivation of the spores was induced by damaging the IM of spores (Setlow et al., 2016). It is known that HPCD has the ability to extract constituents from the cells and cell membrane, modify the structure of cell membrane and damage the proteins, especially enzymes (Garcia-Gonzalez et al., 2007; $\mathrm{Hu}$ et al., 2010). Thus, the lethal effect of the IM damage by HPCD to the spores could be explained as follows: (i) HPCD treatment modified and increased the permeability of the IM of spores. Then, during the spore germination (if the spores are able to germinate) and outgrowth process, the germinated spores plasma membrane, which is derived from the IM of spores, became leaky and were unable to carry out proper energy metabolism (Setlow et al., 2016); (ii) the crucial proteins related to the spore germination and outgrowth in the IM, including the GRs that recognize nutrient germinants, the SpoVA proteins essential for DPA release, and the cortex-lytic enzymes that degrade cortex peptidoglycan (Setlow, 2013), were damaged by HPCD treatment, which in turn, may have induced lethal effects in the spores (Setlow et al., 2016).

Based on our results, HPCD inactivates spores by directly damaging the structures, especially the IM, rather than inducing spore germination. However, it is still not clear how the HPCD precisely acts on and damages the IM of spores. Further studies are required to examine the changes of the properties of the IM, and to identify the specific proteins whose damage induced spore inactivation by the HPCD treatment.

\section{AUTHOR CONTRIBUTIONS}

LR carrying out the experiments and writing the manuscript. FZ giving advice and assistance during the experiments. YW giving advice and assistance during the experiments. FC reviewing the manuscript and giving advice on the manuscript. $\mathrm{XH}$ reviewing the manuscript and giving advice on the manuscript. $\mathrm{XL}$ designing the experiments, reviewing and revising the manuscript.

\section{FUNDING}

This work was supported by Key Project of Chinese Ministry of Education (No. 113011A), Key Project of National Natural Science Foundation of China (NSFC) (No. 31530058 and 21025099), Chinese Universities Scientific Fund (No. 2015SP004), and Beijing Training Project for the Leading Talents in S \& T (No. Z151100000315032).

\section{ACKNOWLEDGMENT}

We are grateful to Prof. Peter Setlow for the advice on the manuscript. 


\section{REFERENCES}

Bae, Y. Y., Lee, H. J., Kim, S. A., and Rhee, M. S. (2009). Inactivation of Alicyclobacillus acidoterrestris spores in apple juice by supercritical carbon dioxide. Int. J. Food Microbiol. 136, 95-100. doi: 10.1016/j.ijfoodmicro.2009.09.015

Bender, G. R., and Marquis, R. E. (1982). Sensitivity of various salt forms of Bacillus megaterium spores to the germinating action of hydrostatic pressure. Can. J. Microbiol. 28, 643-649. doi: 10.1139/m82-096

Black, E. P., Koziol-Dube, K., Guan, D., Wei, J., Setlow, B., Cortezzo, D. E., et al. (2005). Factors influencing germination of Bacillus subtilis spores via activation of nutrient receptors by high pressure. Appl. Environ. Microbiol. 71, 5879-5887. doi: 10.1128/AEM.71.10.5879-5887.2005

Black, E. P., Setlow, P., Hocking, A. D., Stewart, C. M., Kelly, A. L., and Hoover, D. G. (2007a). Response of spores to high-pressure processing. Compr. Rev. Food Sci. Food Saf. 6, 103-119. doi: 10.1111/j.1541-4337.2007. 00021.x

Black, E. P., Wei, J., Atluri, S., Cortezzo, D. E., Koziol-Dube, K., Hoover, D. G., et al. (2007b). Analysis of factors influencing the rate of germination of spores of Bacillus subtilis by very high pressure. J. Appl. Microbiol. 102, 65-76. doi: 10.1111/j.1365-2672.2006.03062.x

Blocher, J. C., and Busta, F. F. (1985a). Multiple modes of inhibition of spore germination and outgrowth by reduced $\mathrm{pH}$ and sorbate. J. Appl. Microbiol. 59, 469-478.

Blocher, J. C., and Busta, F. F. (1985b). Inhibition of germinant binding by bacterial spores in acidic environments. Appl. Environ. Microbiol. 50, 274-279.

Block, S. S. (2001). "Definition of terms," in Disinfection, Sterilization, and Preservation, ed. S. S. Block (London: Lea \& Febiger Press), 19-28.

Brown, K. L. (2000). Control of bacterial spores. Brit. Med. Bull. 56, 158-171. doi: $10.1258 / 0007142001902860$

Coleman, W. H., Chen, D., Li, Y. Q., Cowan, A. E., and Setlow, P. (2007). How moist heat kills spores of Bacillus subtilis. J. Bacteriol. 189, 8458-8466. doi: 10.1128/JB.01242-07

Coleman, W. H., Zhang, P., Li, Y. Q., and Setlow, P. (2010). Mechanism of killing of spores of Bacillus cereus and Bacillus megaterium by wet heat. Lett. Appl. Microbiol. 50, 507-514. doi: 10.1111/j.1472-765X.2010. 02827.x

Damar, S., and Balaban, M. O. (2006). Review of dense phase CO2 technology: microbial and enzyme inactivation, and effects on food quality. J. Food Sci. 71, R1-R11. doi: 10.1111/j.1365-2621.2006.tb12397.x

Devlieghere, F., Vermeiren, L., and Debevere, J. (2004). New preservation technologies: possibilities and limitations. Int. Dairy J. 14, 273-285. doi: 10.1016/j.idairyj.2003.07.002

Enfors, S. O., and Molin, G. (1978). The influence of high concentrations of carbon dioxide on the germination of bacterial spores. J. Appl. Bacteriol. 45, 279-285. doi: $10.1111 /$ j.1365-2672.1978.tb04223.x

Estrada-Girón, Y., Swanson, B. G., and Barbosa-Cánovas, G. V. (2005). Advances in the use of high hydrostatic pressure for processing cereal grains and legumes. Trends Food Sci. Technol. 16, 194-203. doi: 10.1016/j.tifs.2004. 10.005

Fraser, D. (1951). Bursting bacteria by release of gas pressure. Nature 167, 33-34. doi: $10.1038 / 167033 \mathrm{~b} 0$

Furukawa, S., Watanabe, T., Tai, T., Hirata, J., Narisawa, N., Kawarai, T., et al. (2004). Effect of high pressure gaseous carbon dioxide on the germination of bacterial spores. Int. J. Food Microbiol. 91, 209-213. doi: 10.1016/S01681605(03)00372-6

Garcia-Gonzalez, L., Geeraerd, A. H., Spilimbergo, S., Elst, K., Van Ginneken, L., Debevere, J., et al. (2007). High pressure carbon dioxide inactivation of microorganisms in foods: the past, the present and the future. Int. J. Food Microbiol. 117, 1-28. doi: 10.1016/j.ijfoodmicro.2007. 02.018

Hindle, A., and Hall, E. H. (1999). Dipicolinic acid (DPA) assay revisited and appraised for spore detection. Analyst 124, 1599-1604. doi: 10.1039/a906 $846 \mathrm{e}$

Hu, W., Zhang, Y., Wang, Y., Zhou, L., Leng, X., Liao, X., et al. (2010). Aggregation and homogenization, surface charge and structural change, and inactivation of mushroom tyrosinase in an aqueous system by subcritical/supercritical carbon dioxide. Langmuir 27, 909-916. doi: 10.1021/la10 $3482 \mathrm{x}$

Liao, H., Hu, X., Liao, X., Chen, F., and Wu, J. (2007). Inactivation of Escherichia coli inoculated into cloudy apple juice exposed to dense phase carbon dioxide. Int. J. Food Microbiol. 118, 126-131. doi: 10.1016/j.ijfoodmicro.2007. 06.018

Logan, N. A. (2012). Bacillus and relatives in foodborne illness. J. Appl. Microbiol. 112, 417-429. doi: 10.1111/j.1365-2672.2011.05204.x

Mathys, A., Chapman, B., Bull, M., Heinz, V., and Knorr, D. (2007). Flow cytometric assessment of Bacillus spore response to high pressure and heat. Innov. Food Sci. Emerg. 8, 519-527. doi: 10.1016/j.ifset.2007. 06.010

Meyssami, B., Balaban, M. O., and Teixeira, A. A. (1992). Prediction of $\mathrm{pH}$ in model systems pressurized with carbon dioxide. Biotechnol. Prog. 8, 149-154. doi: 10.1021/bp00014a009

Pappas, H. C., Lovchik, J. A., and Whitten, D. G. (2015). Assessing the sporicidal activity of oligo-p-phenyleneethynylenes and their role as bacillus germinants. Langmuir 31, 4481-4489. doi: 10.1021/acs.langmuir.5b00064

Perrut, M. (2012). Sterilization and virus inactivation by supercritical fluids (a review). J. Supercrit. Fluids 66, 359-371. doi: 10.1016/j.supflu.2011. 07.007

Rao, L., Bi, X., Zhao, F., Wu, J., Hu, X., and Liao, X. (2015a). Effect of high-pressure CO2 processing on bacterial spores. Crit. Rev. Food Sci. Nutr. 56, 1808-1825. doi: 10.1080/10408398.2013.787385

Rao, L., Xu, Z., Wang, Y., Zhao, F., Hu, X., and Liao, X. (2015b). Inactivation of Bacillus subtilis spores by high pressure $\mathrm{CO} 2$ with high temperature. Int. J. Food Microbiol. 205, 73-80. doi: 10.1016/j.ijfoodmicro.2015. 04.012

Reineke, K., Ellinger, N., Berger, D., Baier, D., Mathys, A., Setlow, P., et al. (2013a). Structural analysis of high pressure treated Bacillus subtilis spores. Innov. Food Sci. Emerg. 17, 43-53. doi: 10.1016/j.ifset.2012.10.009

Reineke, K., Mathys, A., Heinz, V., and Knorr, D. (2013b). Mechanisms of endospore inactivation under high pressure. Trends Microbiol. 21, 296-304. doi: 10.1016/j.tim.2013.03.001

Sale, A. J. H., Gould, G. W., and Hamilton, W. A. (1970). Inactivation of bacterial spores by hydrostatic pressure. J. Gen. Microbiol. 60, 323-334.

Setlow, B., Korza, G., Blatt, K. M. S., Fey, J. P., and Setlow, P. (2016). Mechanism of Bacillus subtilis spore inactivation by and resistance to supercritical CO2 plus peracetic acid. J. Appl. Microbiol. 120, 57-69. doi: 10.1111/jam. 12995

Setlow, P. (1995). Mechanisms for the prevention of damage to DNA in spores of Bacillus species. Annu. Rev. Microbiol. 49, 29-54. doi: 10.1146/annurev.mi.49.100195.000333

Setlow, P. (2003). Spore germination. Curr. Opin. Microbiol. 6, 550-556. doi: 10.1016/j.mib.2003.10.001

Setlow, P. (2006). Spores of Bacillus subtilis: their resistance to and killing by radiation, heat and chemicals. J. Appl. Microbiol. 101, 514-525. doi: 10.1111/j.1365-2672.2005.02736.x

Setlow, P. (2013). When the sleepers wake: the germination of spores of Bacillus species. J. Appl. Microbiol. 115, 1251-1268. doi: 10.1111/jam.12343

Shah, I. M., Laaberki, M. H., Popham, D. L., and Dworkin, J. (2008). A eukaryotic-like Ser/Thr kinase signals bacteria to exit dormancy in response to peptidoglycan fragments. Cell 135, 486-496. doi: 10.1016/j.cell.2008. 08.039

Spilimbergo, S., and Bertucco, A. (2003). Non-thermal bacterial inactivation with dense CO2. Biotechnol. Bioeng. 84, 627-638. doi: 10.1002/bit.10783

Spilimbergo, S., Bertucco, A., Lauro, F. M., and Bertoloni, G. (2003). Inactivation of Bacillus subtilis spores by supercritical CO 2 treatment. Innov. Food Sci. Emerg. 4, 161-165. doi: 10.1007/s10295-010-0824-4

Spilimbergo, S., Elvassore, N., and Bertucco, A. (2002). Microbial inactivation by high-pressure. J. Supercrit. Fluids 22, 55-63. doi: 10.1016/S08968446(01)00106-1

Wuytack, E. Y., and Michiels, C. W. (2001). A study on the effects of high pressure and heat on Bacillus subtilis spores at low pH. Int. J. Food Microbiol. 64, 333-341. doi: 10.1016/S0168-1605(00)00478-5

Yi, X., and Setlow, P. (2010). Studies of the commitment step in the germination of spores of Bacillus species. J. Bacteriol. 192, 3424-3433. doi: 10.1128/JB.003 26-10 
Zhang, J., Dalal, N., Gleason, C., Matthews, M. A., Waller, L. N., Fox, K. F., et al. (2006a). On the mechanisms of deactivation of Bacillus atrophaeus spores using supercritical carbon dioxide. J. Supercrit. Fluids 38, 268-273. doi: 10.1016/j.supflu.2006.02.015

Zhang, J., Dalal, N., Matthews, M. A., Waller, L. N., Saunders, C., Fox, K. F., et al. (2007). Supercritical carbon dioxide and hydrogen peroxide cause mild changes in spore structures associated with high killing rate of Bacillus anthracis. J. Microbiol. Methods 70, 442-451. doi: 10.1016/j.mimet.2007.05.019

Zhang, J., Davis, T. A., Matthews, M. A., Drews, M. J., LaBerge, M., and An, Y. H. (2006b). Sterilization using high-pressure carbon dioxide. J. Supercrit. Fluids 38, 354-372. doi: 10.1016/j.supflu.2005.05.005
Conflict of Interest Statement: The authors declare that the research was conducted in the absence of any commercial or financial relationships that could be construed as a potential conflict of interest.

Copyright (c) 2016 Rao, Zhao, Wang, Chen, Hu and Liao. This is an open-access article distributed under the terms of the Creative Commons Attribution License (CC BY). The use, distribution or reproduction in other forums is permitted, provided the original author(s) or licensor are credited and that the original publication in this journal is cited, in accordance with accepted academic practice. No use, distribution or reproduction is permitted which does not comply with these terms. 